\title{
LAS RELACIONES DE FIESTAS DEL REINO DE GUATEMALA (1663-1814): LA CONSTRUCCIÓN DEL CORPUS
}

\author{
The festival relationships of the kingdom of Guatemala (1663-1814): \\ The construction of the corpus
}

\section{Alexander Sánchez Mora*}

\section{RESUMEN}

Este artículo ofrece un inventario pormenorizado de las relaciones de fiestas del antiguo reino de Guatemala, el cual comprendía desde los estados mexicanos de Chiapas hasta la actual República de Costa Rica, desde 1663 hasta 1814. Con ello, se intenta subsanar la situación de desconocimiento generalizado sobre este género literario que predomina entre los investigadores del área, al tiempo que promueve el estudio de esta larga tradición textual.

Palabras clave: Literatura colonial, literatura barroca, reino de Guatemala, Centroamérica, relaciones de fiestas, relaciones de sucesos.

\begin{abstract}
This article offers an inventory of the Baroque festivals of the ancient kingdom of Guatemala, which ranged from the Mexican states of Chiapas to the present Republic of Costa Rica, from 1663 to 1814. With this, an attempt is made to correct the situation of widespread ignorance about this literary genre that predominates among researchers in the area, while promoting the study of this long textual tradition.

Key Words: Colonial literature, Baroque literature, Kingdom of Guatemala, Central America, Baroque festivals, news pamphlets.
\end{abstract} *Universidad de Costa Rica. Doctor. Escuela de Filología, Lingüística y Literatura. Costa Rica
Correo electrónico: alexander.sanchez@ucr.ac.cr

Recepción: 12/09/2018.

Aceptación: 09/04/2019. 


\section{La visibilización de un género olvidado}

Todo campo del saber se define a partir de la delimitación de su objeto: un corpus. En el caso de las relaciones de fiestas del reino de Guatemala, ese objeto, hasta el momento presente, no existía como tal. Tan solo unas relaciones aisladas habían captado la atención de algunos investigadores: por lo general, las más llamativas por su riqueza descriptiva y por las amplias colecciones de grabados con que dan cuenta de las arquitecturas efímeras y de sus programas emblemáticos. La relación Guatemala por Fernando Séptimo el día 12 de diciembre de 1808 (1810) de Antonio de Juarros y Lacunza es el mejor ejemplo de esta situación, pues se cuenta con al menos cuatro artículos recientes sobre ella. La razón de tan inusitado interés estriba en el programa iconográfico que decoró el tablado de la proclamación y que es recogido en una serie de veinte extraordinarios grabados de José Casildo España, Francisco Cabrera y Manuel Portillo. ${ }^{1}$ Otra relación que ha despertado cierto interés es El sentimiento del alma, y llanto de la Monarquía de España en la muerte de su reina tres veces, la señora Doña Isabel Farnesio (1768) de Miguel Fernández de Córdoba. Este libro constituye una de las más relevantes colecciones de emblemas guatemaltecos gracias al amplio despliegue visual de cuarenta grabados que reproducen los jeroglíficos, más uno correspondiente al túmulo. Si se exceptuan casos como los dos expuestos, las relaciones

\footnotetext{
${ }^{1}$ Jordana Dym (2009) estudió los emblemas del tablado como expresión de una lealtad condicional, es decir, como un intento de afirmación de una identidad guatemalteca en igualdad de condiciones ante España. Ninel Valderrama Negrón (2011) analizó los ejes iconográficos del programa emblemático -la apoteosis de Fernando VII, el pasado de Guatemala, los modelos académicos (Historia y envidia) - y propuso que la ambigüedad de la arquitectura efímera como tablado-pira da pie a la configuración de Fernando VII en tanto que héroe mítico que retornará de la muerte-prisión. Inmaculada Rodríguez Moya (2015) ha ubicado la relación dentro del contexto general de las juras reales en la monarquía hispánica y de las proclamaciones en Iberoamérica, además de considerar el papel didáctico, conmemorativo y de persuasión ideológica de qué ser revistió la emblemática reproducida en la relación. Por último, Sánchez Mora (2017) se ha referido a dicha relación como un complejo intento de amalgamar la lealtad a la corona con un decidido proyecto de afirmación de la identidad local.
} 
festivas centroamericanas no han merecido la atención de parte de la crítica especializada, a pesar del notable incremento en el estudio del fasto Barroco hispanoamericano durante las últimas décadas. $^{2}$

En cuanto a estudios de carácter general, hasta hace poco solo se contaba con el trabajo Los túmulos funerarios en Guatemala (2012) de Heinrich Berlin y Jorge Luján Muñoz, el cual ocupa un destacado sitial por su carácter pionero y por la amplitud de relaciones que contempla. Los estudiosos mencionados realizan un recorrido descriptivo por los túmulos o piras que engalanaban las exequias de los miembros de la familia real, obispos y nobles, de lo que se deriva su gran valor como fuente de información sobre una buena cantidad de relaciones de festejos fúnebres. ${ }^{3}$ Este afán panorámico, una de las mayores virtudes de la investigación, constituye paradójicamente su mayor limitación, pues conduce hacia el predominio de la descripción de las arquitecturas efímeras y deja poco espacio a la descodificación de sus simbolismos, así como a la contextualización histórica. A pesar de ello, Los túmulos funerarios en Guatemala se erige aún como un modelo por imitar que, de forma lamentable, no llegó a constituir escuela.

Hasta el momento, no se cuenta tampoco con una buena cantidad de ediciones modernas, críticas o no, de los textos festivos centroamericanos. Es posible, aunque esto no sea más que una hipótesis, que el mayor atractivo de las espléndidas celebraciones en los

\footnotetext{
2 Sin ánimos de exhaustividad, se puede mencionar una buena cantidad de trabajos que expresan esta preocupación por el estudio de las fiestas hispanoamericanas: José Miguel Morales Folguera (1986 y 1991 ), José María Díez Borque (1986), Ángel López Cantos (1992), Juan Pedro Viqueira Albán (1995), Rafael Ramos Sosa (1997), Dalmacio Rodríguez Hernández (1998), Pilar Cruz Zúñiga (2001), Palma Martínez-Burgos García y Alfredo Rodríguez González (2004), María J. de la Torre Molina (2004), Juan Manuel Martínez Silva (2004), José Luis Villar Piñeiro (2006), María Águeda Méndez (2009), Judith Farré Vidal (2009), María José Rodilla (2011).

${ }^{3}$ Los autores construyeron su corpus a partir de la información ofrecida por la clásica obra del bibliógrafo chileno José Toribio Medina, La imprenta en Guatemala (1660-1821) (1910). Luján Muñoz publicó una segunda edición revisada en el 2012.
} 
grandes centros poblacionales de la América virreinal haya atraído la mayoría de los esfuerzos académicos. El resultado es un significativo desconocimiento de cómo organizaban y vivían las comunidades periféricas los grandes motivos festivos de la sociedad barroca y, de forma paralela, cuáles eran las prácticas de escritura que intentaban armonizar el despliegue de lujo y derroche barrocos con las limitaciones propias de las provincias más pobres y alejadas de las urbes virreinales.

Entre las pocas ediciones modernas debe citarse, como primera manifestación, la de la relación en verso por el decimotercer cumpleaños de Carlos II de Francisco Antonio de Fuentes y Guzmán, que realizara Justo Zaragoza en 1892. ${ }^{4}$ Habría que esperar más de medio siglo para que se reprodujera otra relación guatemalteca: David Vela (1959) publica, en forma parcial, el Certamen poético... que acompañaba el Diario célebre (1673) con el que Roque Núñez celebró la canonización de San Pedro Pascual de Valencia por parte de Clemente X. La primera edición completa de una relación centroamericana data apenas de 1974, cuando Pérez Alonso publicó la relación doble de Pedro Ximena sobre las exequias de Carlos III y la subsecuente proclamación de Carlos IV en la ciudad de Granada (1793).

Los trabajos de edición más completos son los que han llevado a cabo Héctor M. Leyva, Luis Navarro García y Fernando Navarro Antolín. Leyva reunió en un solo volumen la relación de las fiestas de proclamación del primer arzobispo de Guatemala y un texto satírico, ambos de Antonio de Paz y Salgado: Las luces del cielo de la Iglesia / El mosqueador añadido (2006). Por su parte, Navarro García y Navarro Antolín (2016) se ocuparon de las exequias del obispo de Ciudad Real, tanto en esta urbe como en Santiago de Guatemala: Las dobles exequias del obispo Figueredo (1765). El canto del cisne de los jesuitas en

\footnotetext{
${ }^{4}$ Zaragoza ofrece un resumen de los paratextos (aprobaciones, licencias, décimas y sonetos dedicatorios, pero sí reproduce en forma íntegra los versos de Fuentes y Guzmán (1892, pp. 435-451).
} 
Guatemala. Por último, Sánchez Mora (2016) editó la Breve relación... por el recibimiento del arzobispo Juan Félix de Villegas en la ciudad de Guatemala en 1794.

A pesar de estos notables esfuerzos, la gran mayoría de los textos celebratorios centroamericanos, carentes de grabados, ha pasado desapercibida. A estas circunstancias se suman las precarias condiciones de conservación de los textos en el territorio centroamericano que propiciaron su dispersión, en el mejor de los casos, en bibliotecas y archivos de América y Europa. ${ }^{5}$ Dadas estas condiciones, las relaciones festivas de esta área no son, por lo general, incluidas dentro de los estudios del fasto Barroco novohispano o, en el mejor de los casos, son mencionados como una extensión de las prácticas escriturales mexicanas, sin considerar que responden a un entorno particular marcado por el carácter periférico de la Audiencia de Guatemala.

Ante este panorama, nuestra reciente investigación, Literatura y fiesta en las márgenes del imperio: las relaciones de fiestas en Centroamérica, s. XVII a XIX (2015), pretende constituirse en una primera aproximación, amplia y general, al fenómeno de la fiesta contada barroca en este ámbito geográfico. A continuación, se ofrece un repertorio de las relaciones festivas impresas centroamericanas que ha sido posible localizar hasta el momento. El corpus está formado por cuarenta y tres relaciones, de las cuales treinta y seis corresponden a festejos de la capital del reino en sus dos asientos -Santiago de los Caballeros y Nueva Guatemala de la Asunción-, en tanto que dos son de Chiapas, dos de El Salvador y tres de Nicaragua. El catálogo se organiza, en primera instancia, de conformidad con un criterio geográfico administrativo que sigue la división política del reino de Guatemala. Así,

\footnotetext{
${ }^{5}$ Kramer, Lovell y Lutz (2014) dan cuenta del saqueo al que han sido sometidos los archivos guatemaltecos, tomando como base el caso del extravío - y reciente hallazgo- del Libro Segundo de Cabildo de Santiago de Guatemala.
} 
las relaciones han sido agrupadas de conformidad con su procedencia: Guatemala, Chiapas, El Salvador y Nicaragua. No ha sido posible localizar, hasta el momento, ninguna relación impresa de festejos celebrados en Honduras y Costa Rica, lo que explica la ausencia de toda referencia a dichas jurisdicciones. Además, se ha respetado el orden cronológico de impresión de los textos. Se señala el autor de cada relación -cuando es conocido-, el año de publicación, el título completo, el sitio de edición y la imprenta. Se ofrece información sobre su localización actual —con su respectiva signatura cuando ha sido posible-, los catálogos bibliográficos y otros libros que mencionan cada relación, los estudios académicos que las han abordado y las ediciones modernas con que se cuenta.

\section{Catálogo de las relaciones de fiestas del reino de Guatemala}

\subsection{Guatemala}

1) Avilés, Fr. Esteban. 1663. Festivo obsequio al misterio de la concepción de la reina de los Ángeles, la siempre Virgen María, celebrado (como titular) en su convento de la Concepción de la Ciudad Vieja, o Almolonga; y ejecutado por orden de nuestro gran monarca, y Señor Felipe IV, el grande, en la publicación del Decreto sacro, contenido en la Bula de Alexandro VII que en favor de dicho Misterio despachó por el año de 1662. Su breve descripción, y general epílogo de las demás fiestas en esta ciudad de Guatemala, escribió el Padre fray Esteban de Avilés... quien con todo afecto lo consagra al M.R.P. fray Miguel Rumbo... Guatemala: Imprenta de José Pineda Ibarra.

Localización: Biblioteca de la Universidad de Texas en Austin, Benson Collection, LAC ZZ Rare Books GZZ 282.41 AV55. Agradezco al Dr. Miguel Zugasti Zugasti por haber 
facilitado una copia del texto. En la Biblioteca de la Universidad de Granada se guarda otro impreso relacionado con la misma fiesta: el Sermón en la fiesta, que por cédula de su Majestad, celebró... la ciudad de Guatemala, a la Inmaculada Concepción de María Santísima... con ocasión de la nueva constitución de N. SS. Padre Alejandro Séptimo... del jesuita Francisco Rodríguez de Vera, publicada en México por Juan Ruiz en 1663.

Referencias: José Mariano Beristáin de Souza (1980, p. 127), bajo el título de Descripción de las fiestas que hizo Guatemala por la Bula de Alejandro VII: Sollicitude omnium Eclesiarum y elogio de la Concepción Inmaculada de la Virgen María, predicado en ellas; Salazar (1951, p. 356) y Díaz Vasconcelos (1942, pp. 150-151).

2) Anónimo. 1666. Urna sacra y fúnebre pompa, con que los señores presidente y oidores de la real audiencia de esta ciudad de Guatemala, celebraron las reales exequias, a las augustas memorias de la católica majestad de D. Felipe Cuarto el grande, rey de las Españas y de las Indias, que esté en el cielo. Guatemala: José de Pineda Ibarra.

Localización: Biblioteca Nacional de México, Signatura A-H4, encuadernado con [Lafragua 592]; y en la Biblioteca Francisco de Burgoa de la Universidad Autónoma Benito Juárez de Oaxaca. Referencias: Medina (1960, p. 11).

3) Anónimo. 1666. Relación descriptiva de la festiva pompa en las aclamaciones, con que la nobilísima ciudad de Santiago de Guatemala celebró la jura de nuestro muy Católico Monarca Carlos Segundo, que Dios guarde. Dedícase a Don García de Aguilar y de la Cueva, regidor perpetuo, y alférez mayor de la muy noble y leal Ciudad de los Caballeros de Guatemala, y su encomendero por el Rey nuestro Señor. Guatemala: José de Pineda Ibarra.

Localización: Medina (1960, p. 10) la ubica en la Biblioteca Nacional de Guatemala. Sin embargo, en una consulta de sus catálogos manuales, en enero de 2013, no fue posible localizarla. Referencias: Medina (1960, p. 10). 
4) Sosa Troncoso, Antonio de. 1673. Breve diseño de la festiva pompa, y singular regocijo, con que se celebró en el religiosísimo Convento de N. Seráfico Padre S. Francisco, de esta Provincia del Santísimo Nombre de Jesús; de la nobilísima Ciudad de Santiago de los Caballeros de Guatemala, la canonización, y gloriosa corona, con que se adorna (según la declaración de N.M.S.P. Clemente Nono, Pontífice Máximo, de feliz recordación) el Doctor iluminado, dechado de penitencia, y retrato divino del serafín humano Francisco, San Pedro de Alcántara. Escribíalo Antonio de Sosa Troncoso, hermano de la Escuela de Cristo, uno de sus más humildes siervos. Guatemala: José de Pineda Ibarra.

Localización: Biblioteca Palafoxiana. Referencias: Medina (1960, pp. 20-21).

5) Núñez, Roque. 1673. Diario célebre, novenario solemne, pompa festiva, aclamación gloriosa, con que la muy augusta y religiosísima Provincia de la Presentación de Guatemala, del Orden Real de Nuestra Señora de la Merced Redención de Cautivos, celebró, con regocijados júbilos, y filiales afectos, el culto inmemorial del siempre ínclito protomártir de la redentora familia, chanciller mayor de Castilla, obispo de Jaén y Baeza, gobernador de Toledo, titular de Granada, San Pedro Pascual de Valencia. Guatemala: Imprenta de José Pineda Ibarra.

Localización: Biblioteca Nacional de Antropología e Historia de México se conserva el Certamen poético y justa literaria que coronó el solemnísimo novenario que hizo a la canonización de San Pedro Pascual de Valencia y el Novenario solemne... celebra la declaración de culto inmemorial de San Pedro Pascual de Valencia, ambos de Guatemala, 1673. Medina publica el facsímil de la portada en La imprenta en Guatemala, aunque el texto no se localiza en la actualidad en la Sala Medina de la Biblioteca Nacional de Chile; tal facsímil se vuelve a publicar en el Manual gráfico-descriptivo del bibliófilo hispanoamericano (1930, p. 221) y en el Catálogo de libros raros, (1931), ambos de Vindel. 
Referencias: Beristáin de Souza (1981, II, p. 387), Salazar (1951, p. 377), Placer López (1968, p. 437), Gavarrete Escobar (1980, p. 166). Estudios: Sánchez Mora (2015). Edición: Vela (1959) editó solamente la parte correspondiente al Certamen poético...

6) Fuentes y Guzmán, Francisco Antonio de. 1675. Fiestas reales, en geniales días, y festivas pompas celebradas, a felicísimos trece años que se le contaron a la majestad de nuestro rey, y señor Don Carlos Segundo, que Dios guarde: por la nobilísima, y siempre leal ciudad de Guatemala. Dedícalas la obsequiosa y reverente musa del capitán D. Francisco Antonio de Fuentes y Guzmán, regidor perpetuo de dicha ciudad, al ilustrísimo señor don Fernando Francisco de Escobedo, señor de las Villas de Samayón y Santiz. Guatemala: Imprenta de José Pineda Ibarra.

Localización: Biblioteca Hispánica (AECID), signatura 3GR-7934. Referencias: Palau y Dulcet (1951, V, p. 521). Edición: Fue publicada, en 1882, por Justo Zaragoza, como anexo en su edición de la Recordación florida de Fuentes y Guzmán.

7) Paz, Francisco Javier. 1726. El rey de las flores, o la flor de los reyes: Rosa de Castilla despojada de la primavera de sus años. Aparato fúnebre y canciones lúgubres, con que la ciudad de Guatemala lloró la desgraciada muerte del señor don Luis I de España: con el elogio fúnebre pronunciado en sus exequias. Guatemala: Imprenta del Bachiller Antonio Velasco.

Localización: En la John Carter Brown Library existe un ejemplar de la relación propiamente dicha (puede consultarse en http://archive.org/details/elreydelasflores00pazf). El volumen conservado en la Sala Medina de la Biblioteca Nacional de Chile, signatura III132 (79), contiene, asimismo, el sermón latino de Fr. Carlos Cadena y el castellano del Dr. Isidro de Sicilia y Montoya. Referencias: Beristáin de Souza (1981, p. 458), Medina (1960, pp. 67-68), Palau y Dulcet (1959, XII, p. 391) y Salazar (1951, p. 382). 
8) Anónimo. 1730. “Crónica de las fiestas de toma de posesión del obispo de Guatemala Doctor Juan Gómez de Parada y Mendoza”. En: Gazeta de Guatemala, ․․ 9. Referencias: Medina (1960, p. 70-72), Luján Muñoz (2011, pp. 153-155) y Estrada Monroy (1973, T. I, p. 431). Edición: breve relación reproducida por Medina (1960, pp. 70-72).

9) Vásquez de Molina, Juan. 1732. El santo tapado, y descubierto el mártir oculto. Sermón predicado en las solemnes fiestas que la provincia augusta de Nuestra Señora de La Merced... de Guatemala celebró en la declaración del culto y canonización del mártir San Serapio, etc. Descripción poética de las plausibles fiestas con que la real y militar provincia de Nuestra Señora de la Merced, celebró la canonización del mártir San Serapio. Guatemala: Imprenta de Sebastián Arévalo.

Localización: En la Biblioteca Nacional de Chile, Sala Medina, se encuentra solo el sermón, mas no la relación festiva. Aún en abril de 2014, el catálogo de la British Library consignaba la existencia de un ejemplar de la descripción en $4^{\circ}, 19$ hojas, 13 fols. Sin embargo, al solicitar una reproducción digital, esta fue su respuesta: "Unfortunately the item has been destroyed from our collection this will probably have been during World War II when the Library was hit. We do have to keep a record of the item on our catalogue the prefix D at the beginning of the shelfmark denotes destroyed". Referencias: Medina (1960, p. 76), Díaz Vasconcelos (1942, p. 442), Palau y Dulcet (1973, XXV, p. 364) indica que "La descripción de las últimas 11 páginas corre por separado”.

10) Cagiga y Rada, Agustín de la. 1739. Fúnebre pompa y exequial aparato que celebró en su iglesia catedral, el Ilmo. y Rmo. Sr. Mro. D. Fr. Pedro Pardo de Figueroa del Sagrado Orden de los Mínimos de S. Francisco de Paula, dignísimo obispo de Guatemala, y... En las honras de la M. Ilustre señora $D^{a}$ Petronila Ignacia de Esquivel, Espínola 
Villavicencio, Pardo de Figueroa, marquesa de Valle-Umbroso. Guatemala: Imprenta de Sebastián de Arévalo.

Localización: Biblioteca Nacional de Chile, Sala Medina, FHA 178.17; y Biblioteca Nacional del Perú. Referencias: Beristáin de Souza (1980, p. 237) y Palau y Dulcet (III 1950, p. 31).

11) López Prieto, Nicolás. 1742. El Argos de su iglesia: sermón panegírico y fúnebre que en las honras de Fr. Antonio López Portillo, obispo de Honduras, predicó el M.R.P. Nicolás López Prieto.

Localización: Biblioteca Nacional de España y Biblioteca Nacional de Antropología e Historia de México, 0033F9. En la Biblioteca de la Universidad de Indiana se encuentra El llanto de las virtudes en las exequias del illmo. y rmo. señor d. fr. Antonio de Guadalupe López Portillo... obispo de Comayagua, provincia de Honduras, que dispuso el m.r.p. mro. Juan García de Alva... catedrático de filosofía en este Colegio de Santiago de los Caballeros de Guatemala, el día 17 de abril del año de 1742... de Juan García de Alva. Referencias: Beristáin de Souza (1981, p. 210) menciona un Fr. Nicolás López, franciscano, autor de la Vida del P. Fr. Pedro de Ávila y Ayala.

12) Paz y Salgado, Antonio de. 1747. Las luces del cielo de la iglesia difundidas en el hemisferio de Guatemala, en la erección de su iglesia en metropolitana, e institución de su primer arzobispo, el Ilmo. y Rmo. señor maestro D.F. Pedro Pardo de Figueroa, del Sagrado Orden de los Mínimos.... en que se comprende una breve Relación Histórica del estado de esta Iglesia hasta su feliz exaltación; diligencias para esto hechas, y resumen de las festivas demostraciones con que se ha celebrado la concesión de esta gracia... y a su continuación las oraciones panegíricas, que en sus respectivos días se dijeron en esta santa iglesia metropolitana. Cuyo V. Sr. Deán y Cabildo dándolo todo a luz pública lo dedica, y 
consagra al mismo Ilmo. y Rmo. Señor Arzobispo. México: Imprenta Real del Superior Gobierno y del Nuevo Rezado de Doña María de Ribera.

Localización: Biblioteca Nacional de Guatemala, Sección Antigua, Nivel Octavo, Vitrina 1, 119; Biblioteca Nacional de México, 000001257; y Biblioteca de la Universidad de Indiana. Referencias: Beristáin de Souza (1981, p. 457) y Palau y Dulcet (1959, XII, p. 397). Estudios: Sánchez Mora (2018a). Edición: Las luces del cielo de la iglesia. El mosqueador añadido de Héctor M. Leyva (2006).

13) Molina, Francisco Javier de. 1747. El rey de las luces, luz de los reyes, encendida sobre el candelero de la fúnebre pira, para aclarar desengaños a los soberanos, y enseñarles las más heroicas virtudes, Felipe V. el animoso, imagen de un príncipe perfecto, que sombreaba con los resplandores del fuego e iluminaba con el resplandor de sus virtudes el M.R.P. Francisco Xavier de Molina, profeso de la sagrada Compañía de Jesús, y prefecto de la congregación de Nuestra Señora de la Anunciata en este colegio, cuando describía las suntuosas exequias de su majestad, que celebró el Real Acuerdo de la muy noble, y leal ciudad de Santiago de los Caballeros de Guatemala, los días 16 y 17 de marzo, del año de 1747 a disposición del encendido celo del M. ilustre Sr. D. Tomás de Ribera, y Santa Cruz... capitán general de este reino, quien lo saca a la luz pública, para monumento de su fidelidad, y gratitud y lo consagra al real, y supremo colegio de indias. México: viuda de Joseph Bernardo de Hogal.

Localización: Biblioteca Nacional de México; Biblioteca Nacional de Chile; y Universidad de Berkeley, x F1207. C516 no.2. Referencias: Berlin y Luján Muñoz (2012, pp. 30-33), Beristáin de Souza (1981, pp. 314-315), Palau y Dulcet (1956, IX, pp. 474-475), Mínguez et al. (2012, p. 402) y Luján Muñoz (2010, p. 150), quien señala que también se levantó un túmulo en Cobán, Alta Verapaz, del que se conserva un grabado. 
14) López Portillo y de Camberos, Francisco. 1747. Relación histórica de las reales fiestas que la muy noble, y muy leal Ciudad de Santiago de los Caballeros de Guatemala, celebró desde el día 8 de abril de 1747 años en la proclamación dentro. católico monarca, el Sr. D. Fernando VI, rey de España y de las Indias (que Dios guarde). Guatemala: Imprenta de Sebastián Arévalo.

Localización: Biblioteca Hispánica (AECID), 3GR-7933. Referencias: Palau y Dulcet (1954, VII, p. 659) y Valenzuela (1934, p. 13), quien indica: “Citado en el Catálogo de Libros antiguos, raros y curiosos de Gabriel Molina, Sucesores, Madrid, con este dato: 'Entre los festejos que se celebraron figura una corrida de toros'” (1934, pp. 13-14).

15) Cilieza Velasco, Miguel de. 1751. Los talentos mejor multiplicados en las gloriosas hazañas de un príncipe y pastor caballero, el Illmo. y Rmo. Señor Mro. D. F. Pedro Pardo de Figueroa de el Sagrado Orden de los Mínimos de San Francisco de Paula, obispo de esta Santa Iglesia de Santiago de Guatemala y su primero Dignísimo Arzobispo, de el Consejo de su Majestad, etc... Guatemala: Imprenta de Sebastián Arévalo.

Localización: Biblioteca Nacional de Chile, Sala Medina, FHA 179.2; y British Library. Referencias: Medina (1960, pp. 106-107), Salazar (1951, p. 363) y Palau y Dulcet (1950, III, p. 492). Este último indica que el sermón circuló en tirada aparte: El pastor de ocho talentos (10 h., 32 p.).

16) Arcos y Moreno, Alonso de. 1759. Relación individual de las fiestas, con que se celebró la dedicación del suntuosísimo templo del Calvario de Esquipulas. Y la traslación de la milagrosísima imagen de Cristo crucificado, que se veneraba en el templo viejo, a este su templo nиevo. Guatemala: Imprenta de Sebastián de Arévalo.

Localización: Biblioteca Nacional de Colombia. Referencias: Medina (1960, pp. 124-125), Palau y Dulcet (1948, I, p. 447). Estudios: Sánchez Mora (2018b). 
17) Díaz Freile, Manuel, Batres, José y Manuel Mariano Iturriaga. 1759. El dolor Rey, sentimiento de N. Católico Monarca el señor D. Fernando VI, el Justo. En la sensible muerte de nuestra reina, y señora Dña. María Bárbara de Portugal. Pompa fúnebre, que a la memoria de esta heroína, dispuso en Guatemala, el Sr. D. Manuel Díaz Freile del consejo de S. M., su oidor, y alcalde de corte. Tristes endechas, que para llorar tan temprana desgracia, compuso el P. Manuel Mariano de Iturriaga de la Compañía de Jesús, Guatemala: Imprenta de Sebastián de Arévalo.

Localización: Biblioteca Nacional de Chile, Sala Medina, FHA 179.6; Library of Congress, 17004626; Biblioteca Hispánica (AECID); Seminario mayor o Conciliar de San Julián (Cuenca); y Brown University. Referencias: Medina (1960, pp. 125-126), Mínguez et al. (2012, p. 402) y Berlin y Luján Muñoz (2012, pp. 37-40). Vela (1944) consigna una supuesta Pompa fúnebre con que la ciudad de Guatemala honró la memoria de doña María Bárbara de Portugal, reina de España, esposa del rey don Fernando VI, en prosa y verso. Sin embargo, tal parece que no se trata de un texto independiente, sino de una derivación del título de El dolor rey...; esto se comprueba gracias a la afirmación de Justo Sierra quien, basándose en Beristáin y en el Diccionario de historia y geografía (1853-1856), señala que entre las obras del P. Iturriaga se encuentra "EL Dolor Rey, pompa fúnebre con que la ciudad de Guatemala honró la memoria de la reina de España María Bárbara de Portugal, esposa de Fernando VI (Guatemala, Imprenta de Arévalo, 1759)” (1985, p. 293). Tal parece que Vela eliminó la parte inicial del título consignado por Beristáin, con lo que se creó la ilusión de estarse ante una relación diferente.

18) Valle, Blas del. 1760. Simbólica oliva de paz, y piedad. Descripción del magnífico funeral, que el amor, y la lealtad previnieron a la tierna, y dulce memoria del señor Don Fernando VI, el Justo y Pacifico: cuyo suntuoso túmulo, se adornó con los jeroglíficos que 
siguieron este hermoso símbolo... a dirección del señor... Basilio de Villarraza y Venegas... por el R. Blas del Valle del Orden de Predicadores. Guatemala: Imprenta de Sebastián de Arévalo.

Localización: Real Academia de la Historia, Madrid. Referencias: Medina (1960, p. 130), Mínguez et al. (2012, pp. 402-403) y Berlin y Luján Muñoz (2012, pp. 40-44).

19) Batres, Manuel de. 1761. Relación de las fiestas reales que la noble y fidelísima Ciudad de los Caballeros de Santiago de Guatemala, hizo en la jura del rey nuestro señor D. Carlos III. Guatemala: Imprenta de Sebastián de Arévalo.

Localización: Biblioteca Nacional de Chile, Sala Medina. Referencias: Medina (1960, pp. 131-132), Díaz Vasconcelos (1942, p. 170) y Palau y Dulcet (1949, II, p. 113).

20) Dighero, Juan Antonio. 1763. El Panteón Real, fúnebre aparato a las exequias, que en la Ciudad de Santiago de los Caballeros de Guatemala, se hicieron por el alma, y a la piadosa memoria de nuestra católica reina y señora, Doña Amalia de Sajonia. Guatemala: Imprenta de Sebastián de Arévalo.

Localización: Biblioteca Nacional de Chile, Microformatos, FHA 179. Referencias: Medina (1960, pp. 134-135), Díaz Vasconcelos (1942, pp. 412-413), Palau y Dulcet (1951, IV, p. 461) y Mínguez et al. (2012, p. 403).

21) Sacrameña, Juan José. 1766. Lágrimas de las dos América, la meridional, donde tuvo el más lúcido oriente; la septentrional, donde tuvo el más lúgubre ocaso, el Ilmo. Sol del Sr. Dr. D. Francisco José de Figueredo y Victoria... México: Imprenta del Real y más antiguo Colegio de San Ildefonso de México.

Localización: Real Academia de la Historia, Madrid; y Biblioteca Nacional de México, RLAF 619 LAF. Referencias: Berlin y Luján Muñoz (2012, p. 48) y Palau y Dulcet (1966, XVIII, p. 226). El obispo Figueredo mereció la rara distinción de que se escribieran 
dos libros de exequias, uno sobre los funerales dispuestos por el cabildo metropolitano de Santiago de Guatemala y otro sobre los organizados por los jesuitas de esa misma ciudad (véase numeral 23). Edición: Navarro García y Navarro Antolín (2016) ofrecen una notable edición crítica de ambas relaciones.

22) Molina, P. Francisco Javier. 1766. El llanto de los ojos de los jesuitas de Guatemala en la muerte de su luz, el Ilmo. Sr. Doctor D. Francisco José de Figueredo, y Victoria, obispo, primero de Popayán, y después arzobispo dignísimo de Guatemala. Quien bajo la alegoría de una antorcha luciente sobre el candelero en su vida, se llora apagada en su muerte. Puebla de los Ángeles: Colegio Real de San Ignacio de la Puebla de los Ángeles.

Localización: Real Academia de la Historia, Madrid; Biblioteca Nacional de Chile, Sala Medina, SM 74.3; y Biblioteca Nacional de Colombia. Además del trabajo de Molina, el texto contenía la Funebris declamatio pro iustis... de Rafael Landívar y la Lúgubre declamación... de José Ignacio Vallejo. El ejemplar conservado en Chile contiene el sermón latino de Landívar, en tanto que el preservado en México el de Vallejo. Referencias: Medina (1964, pp. 397-398) y Palau y Dulcet (1956, IX, p. 475). Edición: Navarro García y Navarro Antolín (2016). Véase el numeral 23.

23) Fernández de Córdoba, Miguel. 1768. El sentimiento del alma y llanto de la monarquía de España en la muerte de su reina tres veces, la señora Doña Isabel Farnesio. Parentación lúgubre, y magnifica que en la Ciudad de Santiago de Guatemala se hizo... quien lo dedica a la soberana majestad de nuestro católico monarca el Sr. Don Carlos III. El Sabio... Guatemala: Imprenta de Sebastián de Arévalo.

Localización: Real Biblioteca, Signatura IX/8294. Medina (1960, pp. 146-147) lo ubicaba en el Museo Británico. Referencias: García Pérez (2010), Mínguez et al. (2012, p. 404). Palau y Dulcet (1951, V, p. 309) la describe así: “4, 12 h. 38 fols. 1 gran lámina y otras 
40 láms. grabs. en cobre. Libro raro, de cuya descripción no estamos muy seguros, porque algunos dicen que contiene 4 h. 12 fols. 46 hojas”. Estudios: García Pérez (2010) y Rodríguez Moya (2013).

24) Goicoechea, José Antonio. 1785. Descripción de las honras que en el día 5 de febrero de este presente año de 1785 se dedicaron a la memoria del exmo. señor D. Matías de Gálvez, teniente general de los Reales Ejércitos, virrey, gobernador y capitán general del reino de Nueva España, presidente de su real audiencia, superintendente general de Real Hacienda, y ramo de tabaco, juez conservador de este, presidente de su junta, y subdelegado de la renta de correos en el mismo reino. Costeadas y dispuestas por D. Bernardo Madrid, administrador general de la renta de alcabalas, y barlovento de este reino; y solemnizadas en el convento de monjas de Ntra. Sra. de la Concepción de esta M. N. y Leal Ciudad de Santiago de Guatemala. Oración fúnebre... que predicó el M. R. P. Fr. José Antonio Goicoechea del Orden de S. P. S. Francisco... Guatemala: Impreso por Antonio Sánchez Cubillas.

Localización: Biblioteca de la Universidad de Texas en Austin, Benson Collection LAC Z Rare Books, GZ 972.02 G 139; y Biblioteca de la Universidad de Santiago de Compostela, RSE. PAP.VAR 7 5. Referencias: Beristáin de Souza (1980-1981, p. 35), Medina (1960, p. 191), Díaz Vasconcelos (1942, p. 208), Salazar (1951, p. 369), Bustamante y Urrutia (1956, p. 326).

25) Cadena, Carlos. 1789. Descripción de las Reales exequias que a la tierna memoria de nuestro augusto, y católico monarca el señor D. Carlos III, rey de España, y emperador de las Indias, se hicieron de orden del real acuerdo en la muy noble y leal Ciudad de Guatemala. Guatemala: Imprenta de Ignacio Beteta. 
Localización: Real Biblioteca, X/162; Biblioteca Nacional de Chile, Sala Medina, FHA 182.2; Biblioteca de la Universidad de Harvard. Referencias: Beristáin de Souza (1980, p. 236), Díaz Vasconcelos (1942, p. 169), Palau y Dulcet (1950, III, p. 25), Medina (1960, pp. 215-216) y Mínguez et al. (2012, p. 405).

26) López Rayón, Mariano. 1790. Relación de las fiestas que la muy noble y muy leal Ciudad de Guatemala hizo en la proclamación del Sr. D. Carlos IV. Guatemala: Imprenta de las Benditas Ánimas que dirige Alejo Mariano Bracamonte.

Localización: Biblioteca Nacional de Chile, Sala Medina, FHA 182.4; y Biblioteca Hispánica (AECID) 3GR-8309. Referencias: Palau y Dulcet (1954, VII, p. 660) y Medina (1960, pp. 222-224).

27) Cadena, Carlos. 1793. Breve relación de la solemnidad y augusta pompa con que se recibió en la capital del reino de Guatemala el real sello de nuestro reinante católico monarca el señor Carlos IV. La consagra a la reina nuestra señora doña María Luisa de Borbón el chanciller de la real audiencia del mismo reino d. Juan Miguel Rubio y Gemmir, quien la da a luz y de cuyo encargo la compuso el m.r.p. mtro. provincial fr. Carlos Cadena. Guatemala: Imprenta de Ignacio Beteta.

Localización: Biblioteca Nacional de Chile, Sala Medina, signatura FHA 182.7; Biblioteca Pública de Nueva York, que cuenta con dos ejemplares, signatura KE 1793; y Tulane University, Latin American Library (Rare Books) 972.81 (929.8) C122b. Referencias: Palau y Dulcet (1950, III, p. 25), Medina (1960, p. 251) y Díaz Vasconcelos (1942, p. 169).

28) Estrada, Santiago. 1794. Breve relación de la solemnidad, y augusta pompa con que se recibió en la capital del reino de Guatemala por la Capilla de esta santa iglesia 
metropolitana al M.I.S. D. D. Juan Félix de Villegas dignísimo arzobispo de esta capital. Nueva Guatemala: Imprenta de las Benditas Ánimas de Mariano Bracamonte.

Localización: Biblioteca Nacional de Chile, Sala Medina, FHA 183.6. Referencias: Medina (1960, p. 260) y Palau y Dulcet (1951, V, p. 192), quien afirma que "es una bella muestra de la tipografía de Guatemala. Rara en España”. Estudios: Sánchez Mora (2016). Edición: Sánchez Mora (2016).

29) Anónimo. 1797. Honras fúnebres, que se celebraron en la Iglesia de RR. MM. Capuchinas de la Nueva Guatemala en los días diez, y once de Julio del año 1796 en memoria, y sufragio del señor Don Juan Fermín de Aycinena, Caballero de la Orden de Santiago, primer marqués de Aycinema. Guatemala: Imprenta de Viuda de Sebastián de Arévalo.

Localización: Biblioteca Nacional de Guatemala. Sección Antigua, Nivel Octavo, Vitrina 1, 44. Referencias: Medina (1960, p. 311) y Luján Muñoz (2012, p. 152).

30) Anónimo. 1808. Exequias generales celebradas en la santa iglesia catedral de Guatemala en honor de los ilustres españoles muertos en la santa causa de la religión, el rey y la patria. Guatemala: Ignacio Beteta.

Localización: Biblioteca Nacional de Chile, Sala de Microformatos, SM 109.4 (c. 1) y SM 207.1 (c. 2); Biblioteca Pública de Málaga. Referencias: Medina (1960, p. 450).

31) Anónimo. 1809. Demostraciones públicas de lealtad y patriotismo que el comercio de la ciudad de Guatemala ha hecho en las actuales circunstancias. Guatemala: Imprenta Manuel Arévalo.

Localización: Biblioteca César Brañas. Guatemala, 3091: 8; y Biblioteca Pública de Cádiz, Fondo Antiguo, Folletos CXXXVII, 33. Referencias: Medina (1960, p. 458). Estudios: Sánchez Mora (2018c). 
32) Anónimo. 1809. Relación de las fiestas y actos literarios con que los estudiantes de la real y Pontificia Universidad de Guatemala han celebrado la proclamación del señor Don Fernando VII, la feliz instalación de la Junta central, y los sucesos gloriosos de las armas españolas en la actual guerra contra Napoleón I. Guatemala: Imprenta de Manuel Arévalo.

Localización: Biblioteca César Brañas. Guatemala, 3127, pp. 10, 14; Biblioteca Nacional de Chile, Sala Medina, 111-132 (67); y Biblioteca del Puerto de Santa María, Fondo Antiguo, Siglo XIX REL. Referencias: Medina (1960, p. 466). Estudios: Sánchez Mora (2018c).

33) Juarros y Lacunza, Antonio de. 1810. Guatemala por Fernando VII el día 12 de diciembre de 1808. Guatemala: Impresor Real.

Localización: Real Biblioteca, VI/176 y XIX/4019; y Biblioteca Central de Jerez, N/12028 T/150 F71. Referencias: Medina (1960, pp. 461-462), Mínguez et al. (2012, p. 406) y Luján Muñoz (2011, pp. 158-163). Aunque el libro carece de fecha, “el grabado número 33 es fechado en '1810', y el último texto incluido es la convocatoria de octubre de 1809 para la elección de diputados a Cortes en las Américas y Filipinas, que no habría llegado a Guatemala antes de 1810” (Dym, 2009, p. 78). Todo ello apunta a 1810 como la más probable fecha de publicación. Estudios: Dym (2009), Valderrama Negrón (2011), Rodríguez Moya (2015), y Sánchez Mora (2017).

34) Santa Rosa Ramírez, Fr. Juan de. 1811. Relación sucinta de las honras, y exequias funerales que la Junta de Caridad fundada en el real Hospital de San Juan de Dios de Guatemala, hizo celebrar a expensas de los individuos que la componen, el día 17 de Octubre, de este presente año de 1810. A la buena memoria del ilustrísimo Sr. D. D. Luis de 
Peñalver y Cárdenas, arzobispo que fue de esta diócesis, insigne bienhechor suyo. Guatemala: Imprenta Manuel Arévalo.

Localización: Biblioteca César Brañas, Guatemala, 3091, p. 6; y Biblioteca Nacional de Chile, Sala Medina, 111-132 (69). Aunque Medina consigna un ejemplar en la Biblioteca Nacional de Guatemala, no se logró localizar. Referencias: Palau y Dulcet (1967, XIX, p. 444), Medina (1960, p. 499).

35) García Yáñez, Luis. 1814. Breve relación de las ulteriores fiestas que la Real y Pontificia Universidad hizo en obsequio de su augusto patrono y rey el señor D. Fernando VII. Guatemala: Imprenta de Ignacio Beteta.

Localización: Biblioteca Nacional de Chile, Sala Medina, 111-132 (55). Referencias: Medina (1960, p. 534). Estudios: Sánchez Mora (2018c).

36) Anónimo. Relación de los funerales de José Antonio de Liendo y Goicoechea. Periódico de la Sociedad Económica, N. 8 y 9.

Localización: Biblioteca Nacional de Chile, Sala Medina, 111-86ª (33); y Biblioteca César Brañas, Guatemala, 3355, p. 1. Referencias: Medina (1960, p. 202).

\subsection{Chiapas}

1) Cadena, Felipe. 1768. El sol de la iglesia de Ciudad Real puesto en la cuna de su Oriente. Tiernos lamentos, con que esta amante, dolorida esposa lloró el triste ocaso, y temprana muerte de su dulce esposo, el ilmo. sr. Dr. D. Miguel de Cilieza y Velasco, del Consejo de S.M. y obispo de aquella Diócesis, cuando comenzaba a gozar las benévolas influencias de su luz. Guatemala: Imprenta de Sebastián de Arévalo. 
Localización: Museo del Libro Antiguo, Antigua Guatemala. Referencias: Medina (1960, pp. 144-145), Palau y Dulcet (1950, III, p. 25).

2) Anónimo. 1809. Relación de las demostraciones de fidelidad, amor, y vasallaje que en la solemne proclamación de nuestro soberano augusto el señor D. Fernando VII ha hecho el pueblo de Tapachula, cabecera de la Provincia de Soconusco, intendencia de Ciudad Real de Chiapas en el reino de Guatemala. Guatemala: Imprenta de Ignacio Beteta.

Localización: Biblioteca John Carter Brown de Brown University; Medina lo ubica en el Archivo General de Indias. Referencias: Medina (1960, p. 465). Estudios: Sánchez Mora (2018c).

\subsection{El Salvador}

1) Beira, Bernardo de. 1762. Plausibles fiestas reales y obsequiosa demostración con que la muy leal provincia de Sonsonate, proclamó en su villa de la Santísima Trinidad en el reino de Guatemala, el lunes 19 de Enero de 1761 a su católico monarca, y señor natural (que Dios guarde) Don Carlos Tercero de Borbón, el Magnánimo, y emperador de este Nuevo Mundo. Guatemala: Imprenta de Sebastián de Arévalo.

Localización: Biblioteca Municipal de Betanzos “Alfonso Rodríguez Castelao" XVIII/72; y Biblioteca Nacional de Chile, Sala Medina, FHA 179.10. Referencias: Medina (1960, p. 133). Estudios: Castellón Osegueda (2013).

2) Cadena, Carlos. 1767. El triunfo contra la muerte de la real y generosa águila de España. Sentimientos tristes, que en las fúnebres exequias a la memoria de nuestra católica reina, y heroína Dña. Isabel Farnesio manifestó la muy noble ciudad de San Salvador en el reino de Guatemala. Sácalos a luz, y los consagra a nuestro católico monarca el Sr. D. 
Carlos III (que Dios guarde), el Sargento Mayor de la misma ciudad D. Agustín de Cilieza Velasco. Compuestos por el M. R. P. Fr. Carlos Cadena, del Sagrado Orden de Predicadores. Lector en Filosofía. y Doct. Teólogo en la real universidad de San Carlos de esta corte, y prior actual del convento de San Salvador. Año de 1767. Guatemala: Imprenta de Sebastián Arévalo.

Localización: Museo del Libro Antiguo, Antigua Guatemala. Referencias: Palau y Dulcet (1950, III, p. 25), Medina (1960, p. 142) y Díaz Vasconcelos (1942, p. 247).

\subsection{Nicaragua}

1) Ximena, Pedro. 1793. Reales exequias por el Sr. D. Carlos III, rey de las Españas, y Américas. Y real proclamación de su augusto hijo el señor D. Carlos IV, por la muy noble, y muy leal ciudad de Granada, provincia de Nicaragua, reino de Guatemala. Guatemala: Imprenta de Ignacio Beteta.

Localización: Biblioteca Nacional de España (Sede Recoletos, R/36717). Referencias: Medina (1960, p. 256); Mínguez et al. (2012, p. 405) lo fecha erróneamente en 1790. Edición: Pérez Alonso (1974).

2) Ximena, Pedro. 1795. Oración fúnebre en las solemnes exequias, que el día 28 de Abril de 1795, celebró en su santa iglesia catedral el ilmo. y venerable sr. deán, y cabildo de León de Nicaragua, Por el Ilmo. Sr. D. Esteban Lorenzo Tristán, dignísimo obispo de León, Durango y Guadalajara.

Localización: Biblioteca Nacional de Guatemala. Referencias: Medina (1960, pp. 285-286). 
3) Castillo, Florencio. 1810. Oración fúnebre pronunciada por el Br. Dn. Florencio Castillo, catedrático de Filosofía, y sermón predicado por el Dr. Dn. Francisco Ayerdi, catedrático de Cánones, en las honras funerales del P. Dn. Rafael Ayesta.

Localización: Biblioteca Nacional de Guatemala; Biblioteca Nacional de Chile, Sala Medina, III-132(68). Referencias: Medina (1960, p. 470).

\section{Conclusiones}

El corpus que aquí se propone no pretende ser definitivo. Ulteriores búsquedas en repositorios o archivos poco frecuentados podrían dar cuenta de relaciones hasta ahora desconocidas. A pesar de sus limitaciones, sin embargo, se propone como un necesario punto de partida para un campo hasta ahora poco explorado. Es posible que el mayor aporte de la presente investigación sea la conformación de este corpus de cuarenta y tres relaciones impresas, el cual permite configurar una visión de conjunto de los rituales festivos centroamericanos y, tema de especial interés, de su reformulación literaria. Dar a conocer a la comunidad científica este corpus, de indudable valor histórico y artístico, amplía las posibilidades de penetrar en la comprensión de la recepción e interpretación del fasto Barroco en América. A partir de este conjunto textual, otros investigadores podrán efectuar análisis más detallados que permitirán precisar los detalles del cuadro general del mundo festivo guatemalteco que aquí se esboza.

\section{Referencias bibliográficas}

Berlin, H. y Luján Muñoz, J. (2012). Los túmulos funerarios en Guatemala [1983]. Guatemala: Academia de Geografía e Historia de Guatemala. 
Beristáin de Souza, J. M. (1980-1981). Biblioteca Hispanoamericana Septentrional [18161819]. México: Universidad Nacional Autónoma.

Bustamante y Urrutia, J. M. (1956). Catálogos de la Biblioteca Universitaria. Impresos del siglo XVIII (Tomo III). Santiago de Compostela, España: Editorial de El Eco Franciscano.

Castellón Osegueda, J. R. (2013). Vida, alimentación y fiestas en los territorios del Reino de Guatemala, San Salvador y Sonsonate, siglo XVIII. (Tesis doctoral en Historia de América Latina), Universidad Pablo de Olavide, Sevilla.

Cruz Zúñiga, P. (2001). La fiesta barroca: poder, jerarquía y representación social en Quito, 1766. Procesos. Revista Ecuatoriana de Historia, 17, 35-60.

Díaz Vasconcelos, L. A. (1942). Apuntes para una historia de la literatura guatemalteca. Guatemala: Tipografía Nacional.

Díez Borque, J. M. (Ed.). (1986). Teatro y fiesta en el barroco. España e Iberoamérica. Barcelona: Ediciones del Serbal.

Dym, J. (2009). Enseñanza en los jeroglíficos y emblemas: Igualdad y lealtad en Guatemala por Fernando VII (1810). Secuencia. Revista de Historia y Ciencias Sociales, Número Conmemorativo, 73-99.

Estrada Monroy, A. (1973). Datos para la historia de la Iglesia en Guatemala (Tomo I). Guatemala: Sociedad de Geografía e Historia de Guatemala.

Farré Vidal, J. (2009). Cartografía simbólica de la ciudad de México y pedagogía de virreyes (1665-1700). En J. Farré Vidal (Ed.), Dramaturgia y espectáculo teatral en la época de los Austrias (pp. 167-190). España: Universidad de Navarra-Iberoamericana Vervuert.

García Pérez, F. J. (2010). Las exequias de Isabel de Farnesio en Guatemala, 1767-1768. Imago. Revista de emblemática y cultura visual, 2, 61-77.

Gavarrete Escobar, J. (1980). Anales Para la Historia de Guatemala (1497-1811). Guatemala: José de Pineda Ibarra.

Kramer, W., Lovell, W. G. y Lutz, C. H. (2014). Saqueo en el archivo. El paradero de los tesoros documentales guatemaltecos. Antigua Guatemala: Centro de Investigaciones Regionales de Mesoamérica (CIRMA) / Ciudad de Guatemala: Centro de Estudios Urbanos y Regionales (CEUR) / Wellfleet, Massachusetts: Plumsock Mesoamerican Studies.

Leyva, H. M. (2006). Las luces del cielo de la iglesia. El mosqueador añadido. Tegucigalpa, Honduras: Universidad Nacional Autónoma de Honduras, Editorial Universitaria.

López Cantos, Á. (1992). Juegos, fiestas y diversiones en la América española. Madrid, España: Editorial MAPFRE. 
Luján Muñoz, J. (2010). Nueva antología de artículos de historia del arte, arquitectura y urbanismo. Guatemala: s. e.

Luján Muñoz, J. (2011). Nueva antología de artículos de historia del arte, arquitectura y urbanismo. Guatemala: s. e.

Martínez-Burgos García, P. y Rodríguez González, A.(2004). La fiesta en el mundo hispánico. Cuenca, España: Universidad de Castilla-La Mancha.

Martínez Silva, J. M. (2004). Las fiestas del poder en Santiago de Chile: de la jura de Carlos IV a la jura de la Independencia. F. Guzmán Schiappacasse, G. Cortés y J. M. Martínez (pp. 57-66). Santiago, Chile: RIL Editores.

Medina, J. T. (1960). La Imprenta en Guatemala [1910]. Guatemala: Tipografía Nacional de Guatemala.

Medina, J. T. (1964). La Imprenta en la Puebla de los Ángeles. Amsterdam, Holanda: N. Israel.

Méndez, M. Á. (2009). Fiesta y celebración: discurso y espacio novohispanos. México: El Colegio de México.

Mínguez, V., Rodríguez Moya, I., González Tornel, P. y Chiva Beltrán, J. (2012). La fiesta barroca. Los virreinatos americanos (1560-1808). Castellón de la Plana, España: Publicacions de la Universitat Jaume I; Las Palmas, España: Universidad de Las Palmas de Gran Canaria.

Morales Folguera, J. M. (1986). La fiesta barroca y el arte efímero en el Virreinato de Nueva España. Apotheca, 6, 9-25.

Morales Folguera, J. M. (1991). Cultura simbólica y arte efímero en la Nueva España. Sevilla, España: Junta de Andalucía, Consejería de Cultura y Medio Ambiente.

Navarro García, L. y Navarro Antolín, F. (2016). Las dobles exequias del obispo Figueredo (1765). El canto del cisne de los jesuitas en Guatemala. Huelva, España: Universidad de Huelva.

Palau y Dulcet, A. (1948-1977). Manual del librero hispano-americano (Tomo XXVIII). Barcelona, España: Librería Anticuaria de A. Palau.

Pérez Alonso, M. I. (1974). D Pedro Ximena. Reales exequias, por el señor D Carlos III. Rey las Españas, y Américas. Y real proclamación de su augusto hijo el señor D. Carlos IV. Por la muy noble y muy leal ciudad de Granada, provincia de Nicaragua, reyno de Guatemala. Managua, Nicaragua: Banco Central de Nicaragua.

Placer López, G. (1968). Bibliografía Mercedaria (Tomo II). Madrid, España: Publicaciones del Monasterio de Poyo.

Ramos Sosa, R. (1997). La fiesta barroca en Ciudad de México y Lima. Historia, 30, 263286. 
Rodilla, J. M. (2011). Ciudad lúdica: juegos, diversiones públicas, caballos, libreas y otras galas novohispanas. En C. Parodi y J. Rodríguez (Eds.), Centro y periferia. Cultura, lengua y literatura virreinales en América (pp. 45-57). Madrid, España: Iberoamericana-Vervuert.

Rodríguez Hernández, D. (1998). Texto y fiesta en la literatura novohispana (1650-1700). México: Universidad Nacional Autónoma de México, Instituto de Investigaciones Bibliográficas, Seminario de Cultura Literaria Novohispana.

Rodríguez Moya, I. (2013). La mujer-águila y la imagen de la reina en los virreinatos americanos. Quiroga. Revista de Patrimonio Iberoamericano, 4, 58-75.

Rodríguez Moya, I. (2015). Guatemala por Fernando VII: iconografía y emblemática en el estudio de las Juras Novohispanas. En R. López Guzmán, Y. Guasch Marí y G. Romero Sánchez (Eds.), América: cultura visual y relaciones artísticas (pp. 247256). Granada, España: Universidad de Granada.

Salazar, R. A. (1951). Historia del desenvolvimiento intelectual de Guatemala (Época colonial) [1897]. Guatemala: Editorial del Ministerio de Educación Pública.

Sánchez Mora, A. (2015). Literatura y fiesta en las márgenes del imperio: las relaciones de fiestas en Centroamérica, s. XVII a XIX. [Tesis doctoral, Universidad de Sevilla].

Sánchez Mora, A. (2016). La arquitectura efímera ilustrada: la elevación de un globo aerostático en el recibimiento del arzobispo Villegas (Guatemala, 1794). En I. Rodríguez Moya, M A de los. Fernández Valle y C. López Calderón (Eds.), Arte y patrimonio en Iberoamérica. Tráficos transoceánicos (pp. 477-494). Castellón de la Plana, España: Publicacions de la Universitat Jaume.

Sánchez Mora, A. (2017). Guatemala por Fernando Séptimo: crisis dinástica, juegos de lealtad y afirmación del poder local en una relación de fiestas. Revista de Historia, 75, enero-junio, 159-188.

Sánchez Mora, A. (2018a). Las luces del cielo de la iglesia (1747) de Antonio de Paz y Salgado: la retórica del poder en la proclamación del arzobispado de Guatemala. Fronteras de la Historia, 23(1), 12-38.

Sánchez Mora, A. (2018b). Devoción y promoción personal en el reino de Guatemala: Relación individual de las fiestas con que se celebró la dedicación del suntuosísimo Templo del Calvario de Esquipulas (1759). Potestas. Estudios del Mundo Clásico e Historia del Arte, (13), 101-118.

Sánchez Mora, A. (2018c). Las fiestas de proclamación de Fernando VII en el reino de Guatemala: trasformación y supervivencia de un modelo retórico. Atenea, 517, 221239.

Sierra, J. (1985). Antología del Centenario. Estudio documentado de la literatura mexicana durante el primer siglo de independencia (2. ${ }^{a}$ ed.). México: Universidad Nacional Autónoma de México. 
Torre Molina de la, M. J. (2004). Música y ceremonial en las fiestas reales de proclamación de España e Hispanoamérica (1746-1814). (Tesis doctoral en Historia del Arte y Música). Universidad de Granada, España.

Valderrama Negrón, N. (2011). El artilugio del tiempo en un tablado en honor a Fernando VII en Guatemala. Revista Electrónica Imágenes del Instituto de Investigaciones Estéticas. Recuperado de http://www.esteticas.unam.mx/revista_imagenes/dearchivos/dearch_valderrama01.h tml

Valenzuela, G. (1934). La Imprenta en Guatemala. Algunas adiciones a la obra que con este título publicó en Santiago de Chile el ilustre literato don José Toribio Medina. Guatemala: Tipografía Nacional.

Vela, D. (1944). Literatura guatemalteca. Guatemala: Unión Tipográfica.

Vela, D. (1959). Certamen poético y justa literaria con que la augusta y religiosa Provincia de la Presentación de Goatemala, del Orden de Nuestra Señora de la Merced, Redempcion de Cautivos: Coronó el Solemnísimo Novenario, que hizo a la Canonización y culto inmemorial del Protomartyr Inclito S. Pedro Pasqual de Valencia, Obispo de Jaen, y Baeza. Guatemala: Unión Tipográfica.

Villar Piñeiro, J. L. (2006). Las noticias en la América colonial: dos relaciones de temática indígena. En S. López Poza (Ed.), Las noticias en los siglos de la imprenta manual. Homenaje a Mercedes Agulló, Henry Ettinghausen, Ma. Cruz García de Enterría, Giuseppina Ledda, Augustin Redondo y José Simón. A Coruña, España: SIELAE y Sociedad de Cultura Valle Inclán.

Vindel, F. (1930). Manual gráfico-descriptivo del bibliófilo hispano-americano (1475-1850) (Tomo VI). Madrid, España: Imprenta Góngora.

Vindel, F. (1931). Catálogo de libros raros y curiosos que serán subastados durante los días 4 a 9 de mayo, procedentes de la Librería Bebz, dirigida por Francisco Vindel. Madrid, España: Góngora.

Viqueira Albán, J. P. (1995). ¿Relajados o reprimidos? Diversiones públicas y vida social en la ciudad de México durante el siglo de las Luces. México: FCE.

Zaragoza, J. (1882). Historia de Guatemala o Recordación florida, escrita en el siglo XVII por Francisco Antonio de Fuentes y Guzmán; que publica por primera vez con notas e ilustraciones Justo Zaragoza. Madrid, España: Luis Navarro, editor. 